\title{
Sero-Prevalence and Risk Factors of Diffusion of Peste des Petits Ruminants in Cameroon
}

\author{
Severin Loul ${ }^{1,2}$, Abel Wade ${ }^{3}$, Alexandre Michel Njan Nlôga ${ }^{4}$ \\ ${ }^{1}$ Ministry of Livestock, Fisheries and Animals Industries, Yaounde, Cameroon \\ ${ }^{2}$ Center of Research on Emerging and Reemerging Diseases, Yaounde, Cameroon \\ ${ }^{3}$ National Veterinary Laboratory, Garoua, Cameroon \\ ${ }^{4}$ Faculty of Science, University of Ngaoundere, Ngaoundere, Cameroon \\ Email: severinloul@yahoo.fr, njanalexandre@yahoo.fr, abelwade@gmail.com
}

How to cite this paper: Loul, S., Wade, A. and Nlôga, A.M.N. (2020) Sero-Prevalence and Risk Factors of Diffusion of Peste des Petits Ruminants in Cameroon. Open Journal of Veterinary Medicine, 10, 103-115. https://doi.org/10.4236/ojvm.2020.107009

Received: May 24, 2020

Accepted: July 28, 2020

Published: July 31, 2020

Copyright $\odot 2020$ by author(s) and Scientific Research Publishing Inc. This work is licensed under the Creative Commons Attribution International License (CC BY 4.0).

http://creativecommons.org/licenses/by/4.0/ (c) (i) Open Access

\begin{abstract}
The present study was carried out between April 2015 and January 2016 to estimate the sero-prevalence and identify the risk factors of the peste des petits ruminants (PPR) in Cameroon. A total of 269 herds randomly sampled across the country have been studied and 1622 samples of serum have been levied on the sheep and goat. The c-ELISA has been studied in order to detect the presence of antibodies in small ruminants like an indicator of exposition to PPRV. The results revealed the circulation of PPRV in the country with a total sero-prevalence of $39 \%$ [95\%CI; 37 - 41] and a sero-prevalence of $63.2 \%$ [95\%CI; 57.2 - 69.2] at the herd level. Sero-prevalence was variable in the ten regions ranging from $7 \%$ [95\% CI; 6.2 - 8.4] to $73 \%$ [95\% CI; 62 - 84] with the northern zone (Adamawa, North and Far-North) having 52.3\% [95\% CI; 37 60] and southern zone (including the remaining seven regions) recording 29\% [95\% CI; 11 - 57]. Similarly, it was higher in animals found in urban/peri-urban areas than in rural areas with prevalence ratio of $2.9[95 \% \mathrm{CI}$ 2.54 - 3.4; $\mathrm{p}<0.001$ ] i.e. 3 times more, 1.6 [95\% CI 1.36 - 1.90; $\mathrm{p}<0.001]$ i.e. 1.6 times more, and 5.02 [95\% CI $3.91-6.85 ; \mathrm{p}<0.001]$ i.e. 5 times more at national level, in the northern zone and in the southern area, respectively. Five risk factors have been identified: the breeding environment, introduction of new animals into the herds, gathering of animals for pasture and watering, wandering and transhumance. The breeding area appeared to be the most important risk factor associated with disease exposure. The control measures for the eradication of this disease must take into account the epidemiological situation, the breeding environment, animal transhumance and breeding system.
\end{abstract}




\section{Keywords}

Small Ruminants, Sero-Prevalence, Risk Factors, Peste des Petits Ruminants, Cameroon

\section{Introduction}

The peste des Petits ruminants (PPR) is an infectious disease which is very contagious due to a virus (PPRV), belonging to the gender Morbillivirus of the family of paramyxoviridae [1]. It affects small domestic (goats and sheep) and wild ruminants and is characterized by a feverish invasion, respiratory and digestive involvements and ulcerative and necrotic lesions of the mucous membrane. The PPR has been identified by the World Organization for Animal Health (OIE) as a cross-border viral disease with a mandatory reporting under the conditions in out in the health code for terrestrial animals of the OIE and economically important in sheep and goat due to the high mortality and morbidity in these species [2].

Following the rinderpest eradication and for its epidemiological and economical importance, FAO and L'OIE, choose PPR as a priority in terms of eradication control in the world. Very effective licensed PPR vaccines have been developed and more than 20 laboratories produce these vaccines in Africa [3] [4].

The causal agent, the PPR virus (PPRV), is genetically grouped into (I, II, III, IV) four lineages based on a partial sequence analysis of the gene. The cloned colonies I to III circulate in Africa while lineage IV is in Asia [5]. However Kadidia TOUNKARA discovered the presence of lineages IV in the Southern of Niger [6] and the same cloned colony had already been discovered in Cameroon in 1997, in Gabon [7] and recently in Nigeria by 2018 [8]. These results suggest that lineage IV of Asian origin spreads from East and Central Africa to West Africa where the lineage II is currently predominant [9].

A recent apparition of the lineages IV was associated with a significant epizootic in Morocco, and posed a probable risk of introduction into Europe [9] [10].

The PPR was first described in 1942, in Ivory Coast [6]. From its African candle located between the equator and the Sahara, the disease has spread to reach the Arabian Peninsula, the Middle East, Southeast Asia, India, China and North Africa [11] [12].

The disease principally spreads by direct contact between non-infected animals and infected ones. Extensive breeding systems, seasonal migrations, market and gatherings ease the propagation of the disease. International transhumance is very practiced in the area which brings together the three regions of the North (Far North, North and Adamawa). Indeed, there are several massive movements of breeders and small ruminants from East African countries (Chad, Sudan, Central African Republic), via the three Regions to reach the African countries 
of West (Nigeria, Benin). The risk of spreading the disease is therefore very high [13]. PPR is a very contagious disease which spreads very fast. The contamination sources are different sick animals' excretions: nasal and eye secretions, saliva, feces and urine [1] [14] [15]. The infected animals can excrete the virus about 3 days before the beginning of the sickness [15].

In Cameroon, the PPR is a legally contagious disease with a compulsory declaration throughout the territory [16]. Although recognized as being the source of a significant economic loss in small ruminant production system, its epidemiological situation remains poorly assessed epidemiological situation [17]. The Panafrican control of epizootics (PACE) had put in place a control epidemiological network of animal disease in many African countries like Cameroon. The reporting of clinical suspicions of the PPR from 2005 to 2010 by this network permitted to note that the pest of small ruminants was enzootic in Cameroon due to its presence on the national territory [2] [17].

In this study, we analyze the results of serological investigations carried across the country in order to establish the sero-prevalence of the PPR in sheep and goats and to evaluate the risk propagation factors of the disease.

\section{Materials and Methods}

\subsection{Area and Type of Study}

The study took place on the ten regions of the Country: Far North, North, Adamawa, East, Center, South, South West, North West, West and Littoral. The period of sample collection were from April to September 2015 and laboratory analysis from October 2015 to January 2016. The objective was to determine the sero-prevalence of the PPR, identify the risk factors and measure the association between the dominant risk factors and the disease.

\subsection{Specimens and Samples}

During these transverse investigations, the none-vaccinated herds with PPR with less than 10 animals (sheep and goats) were selected by simple random sampling. Totally, 269 herds were chosen by random selection. Four to five animals aged with more than 6 months (owners' notice and confirmation by observation of the dentition) in each herd were drawn regardless of gender and samples were taken. For each herd which disposed of less than six animals which respect the minimal age, they were all collected. Totally, 1622 samples of small ruminants have been done. Blood was taken from the jugular vein by a $10 \mathrm{ml}$ syringe and introduced into a marked tube with the breeding code and serial number. All the samples were transported in a cooler every evening; they were centrifuged and transferred to cryotubes marked with regional codes, the department, district and direct debit number. These serums were conserved in freezers of departmental delegations, and then transported to the National Veterinary Laboratory (LANAVET) under ice, where they were stocked at temperatures of $-20^{\circ} \mathrm{C}$. 


\subsection{Serological Test}

The samples were diagnosed at the national veterinary laboratory (LANAVET) by a competition Elisa test (Competitive-Enzyme-linked immunosorbent assay) for the detection of antibodies anti-PPRV (c-Elisa PPR). Its use has been done as described by the OIE. The c-Elisa PPR test has been used according to the Libeau and coll protocol [10] [18]. The optic densities (OD) they were read on the Multiskan spectrophotometer EX at a wavelength of $492 \mathrm{~nm}$ and were converted to inhibition percentages (PI) according to the formula: PI $=100-$ [OD of sampled serums/OD of monoclonal control] $\times 100$. The serums with a PI greater than 50 p. 100 have been considered positive. Serums having a PI (inhibition percentage) greater of equal to $60 \%$ are considered positive, those having a PI less or equal to $40 \%$ are considered negative and finally, serums with PI between $41 \%$ and $59 \%$ are doubtful [18].

\subsection{Opinion Poll among Breeders}

In addition to the sample taken from each herd, an opinion poll (survey) on the behavior, attitude and practicals have been administered to every breeder in order to evaluate the transmission and diffusion risks of the disease. The following points have been mentioned in this questionnaire: breeding mode, implantation and breeding ground, purchase or sale of animals, sanitary state, vaccination and herd conduct.

\subsection{Statistical Analysis}

Data has been saved in excel and the STATA software (version 10.0) has been used to determine the national sero-prevalence then, that of each region. The csi function has been used to have an estimation of the RR. The QGIS software (version 2.12.0) has been used for the cartographic representation of results.

\section{Results}

\subsection{Prevalence of the PPR in Cameroon}

\subsubsection{Individual Prevalence}

The serum analysis of the 1622 small ruminants indicates that 643 were positive hence having a serological prevalence of $39.6 \%$ [95\% CI; 37.6 - 41.6]. Though the Peste des petits ruminants was present in all the ten regions, its sero-prevalence varied from one region to another (Table 1).

The average prevalence rate in the northern zone which groups the three regions (Adamawa, North and Far North) is 52\% [95\% CI; 47 - 60]. It is a savannah area and characterized by a long period of dry season. The farming method practiced is dominated by transhumance and also grouping of animals to use the same watering and grazing. In the South zone, which groups the other seven regions (East, Center, South, Littoral, West, Southwest, North West) the average prevalence is $29 \%$ [ $95 \%$ CI; 11 to 57 ]. It is a forest area and characterized by abundance of precipitation (Table 2). 
Table 1. Individual repartition of the prevalence per region.

\begin{tabular}{cccccc}
\hline Region & $\begin{array}{c}\text { Number of } \\
\text { individuals }\end{array}$ & $\begin{array}{c}\text { Number of } \\
\text { positives }\end{array}$ & Prevalence & p-value & CI (95\%) \\
\hline Adamawa & 234 & 145 & 0.62 & 0.000 & {$[0.41-0.73]$} \\
North & 171 & 115 & 0.67 & 0.000 & {$[0.60-0.74]$} \\
Far-north & 340 & 130 & 0.382 & 0.000 & {$[0.33-0.43]$} \\
Center & 152 & 31 & 0.2 & 0.000 & {$[0.14-0.27]$} \\
East & 134 & 19 & 0.142 & 0.000 & {$[0.09-0.20]$} \\
South & 139 & 75 & 0,54 & 0.000 & {$[0.45-0.63]$} \\
Littoral & 58 & 41 & 0.707 & 0.000 & {$[0.59-0.81]$} \\
West & 72 & 32 & 0.44 & 0.000 & {$[0.33-0.56]$} \\
South-west & 206 & 47 & 0.23 & 0.000 & {$[0.17-0.29]$} \\
North-west & 116 & 8 & 0.07 & 0.000 & {$[0.02-0.12]$} \\
National & 1622 & 643 & 0.396 & 0.000 & {$[0.376-0.416]$} \\
\hline
\end{tabular}

Table 2. Prevalence in the northern and southern areas of the country.

\begin{tabular}{ccc}
\hline Epidemiologic situation & Zone & Seroprevalence (95\% CI) \\
\hline $\begin{array}{c}\text { Three septentrional regions } \\
\text { (Adamawa; North; Far-north) } \\
\text { PPR is endemic in } \\
\text { in all the regions }\end{array}$ & $\begin{array}{c}\text { Seven meridional regions (Center; South; } \\
\text { Littoral; West; South-west; North-west) }\end{array}$ & $29 \%(11-57)$ \\
& Entire country & $39 \%(37-41)$ \\
\hline
\end{tabular}

\subsubsection{Herd Prevalence}

Out of 266 herds selected, 170 counted at least one positive animal that is a serological prevalence of 63.2\% [IC95\%; 57.2 - 69.2] (Table 3).

\subsection{Determination of Risk Factors for the Spread of PPR}

The opinion poll of 267 breeders made it possible to identify, in order of importance, five key risk factors, namely; the environment in which the breeding ground was established, the introduction of new animals into the breeding grounds, the gathering of animals grazing or common watering, wandering animals and transhumance with respective opinion percentages of $54 \%, 33 \%, 27 \%, 22 \%$ and $7 \%$. The environment in which the breeding ground is located, appeared to be the most important associated risk factor of the five and has a significant impact in the southern zone compared to the northern zone. Transhumance and the gathering of animals in a common pasture or watering is more practiced in the northern zone than in the southern zone where straying constitutes the dominant mode of breeding. The difference was not so significant in the two areas at the 
risky practice of introducing new animals into the breeding grounds (Figure 1). For other parameters mentioned during the interviews, our results indicate that $49 \%$ of animals sampled were in urban/peri-urban areas, all the farms in our sample were intended to produce meat (no milk production), vaccinated herds were excluded from the survey.

Table 3. Distribution of the prevalence at the herd scale by region.

\begin{tabular}{ccccc}
\hline & $\begin{array}{c}\text { Number } \\
\text { of herds }\end{array}$ & $\begin{array}{c}\text { Number of } \\
\text { positives }\end{array}$ & $\begin{array}{c}\text { Prevalence } \\
\text { of floc }\end{array}$ & $\begin{array}{c}\text { Confidence } \\
\text { interval 95\% }\end{array}$ \\
\hline Adamawa & 60 & 38 & $63.3 \%$ & {$[50.7-76.0]$} \\
North & 24 & 22 & $91.7 \%$ & {$[71.7-100]$} \\
Far-north & 38 & 35 & $92.1 \%$ & {$[76.2-100]$} \\
Center & 22 & 11 & $50.0 \%$ & {$[29.1-70.9]$} \\
East & 28 & 13 & $46.4 \%$ & {$[27.9-64.9]$} \\
South & 17 & 13 & $76.5 \%$ & {$[52.7-100]$} \\
Littoral & 9 & 6 & $66.7 \%$ & {$[34.0-99.3]$} \\
West & 12 & 10 & $83.3 \%$ & {$[55.0-100]$} \\
South-west & 25 & 7 & $28.0 \%$ & {$[8.4-47.6]$} \\
North-west & 34 & 15 & $44.1 \%$ & {$[27.3-60.9]$} \\
National & 266 & & $63.2 \%$ & {$[57.2-69.2]$} \\
\hline
\end{tabular}

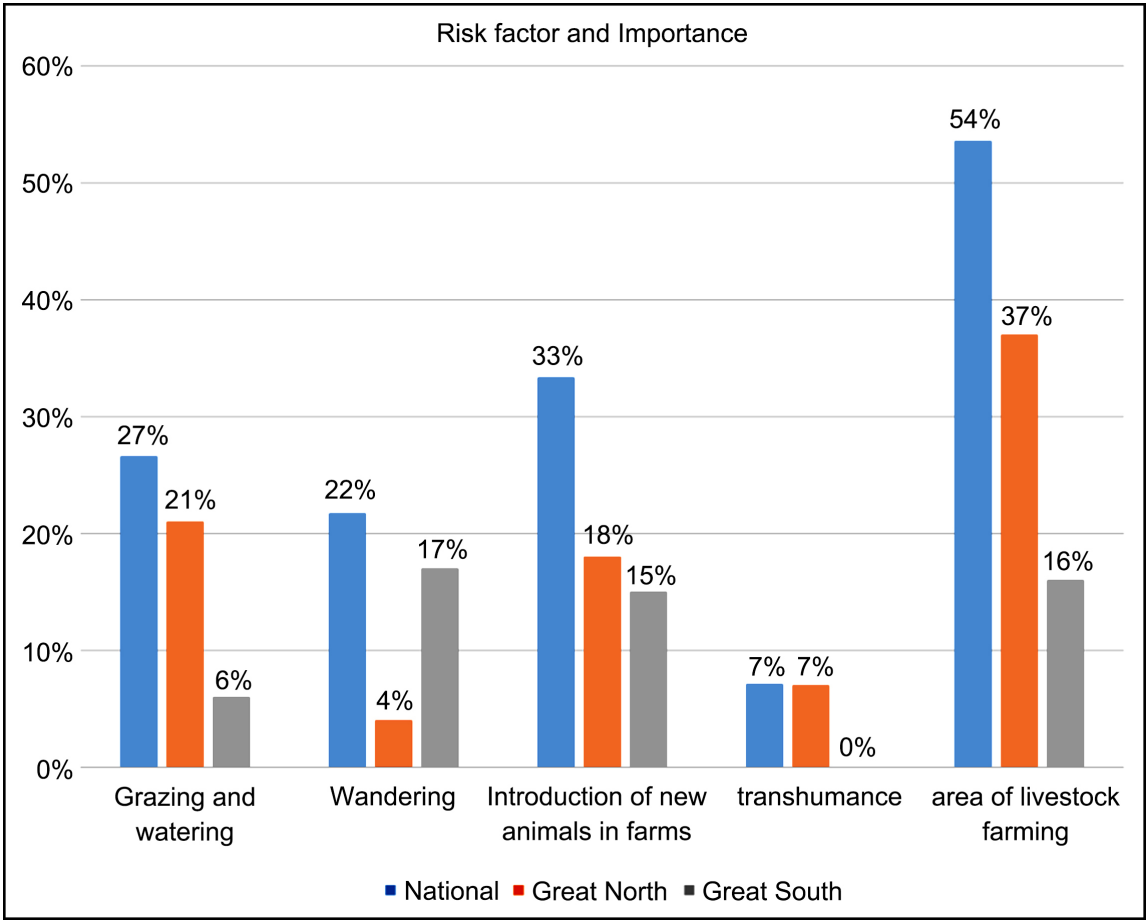

Figure 1. Variation of risk factors and their importance. 


\subsection{Determination of Prevalence on Breeding Grounds Located in Urban/Peri-Urban and Rural Areas}

To measure the risk of exposure of the disease in relation to the setup of breeding grounds either in urban/peri-urban or in rural areas, we calculated the sero-prevalence between animals raised in urban/peri-urban areas with those in rural areas. Overall, the prevalence in herds raised in urban/peri-urban areas is three times higher than in herds raised in rural areas. The prevalence ratio is 2.9; [95\% CI $2.54-3.4 ; \mathrm{p}<0.0001$ ] (Table 4). There is a significant difference between the exposures of the infection in the urban/peri-urban area compared to the rural area. The urban/peri-urban environment appears more exposed to the disease than the rural area.

At the national level, the sero-prevalence of PPR appears to be 3 times higher in animals in urban/ peri-urban breeding grounds as compared to animals in rural area breeding grounds. The urban/peri-urban areas seem to constitute an environment at high risk of exposure to the transmission and diffusion of PPR in small ruminants. However, the prevalence ratio (PR) of PPR between urban/peri-urban and rural areas is lower in the northern area (Adamawa, North and Far North) i.e. RP $(61 / 38)=1.61$ [95\% CI 1.36 - 1.90] compared to the South zone (7 other regions) i.e. RP $(58 / 11)=5.27$ [95\% CI 3.91 - 6.85] (Figure 2). Animals from urban breeding grounds in the Northern zone and the Southern zones are respectively 1.6 and 5 times more exposed to PPR as compared to animals from rural breeding grounds. The urban/peri-urban environment or area seems to constitute an associated risk factor which facilitates the spread of

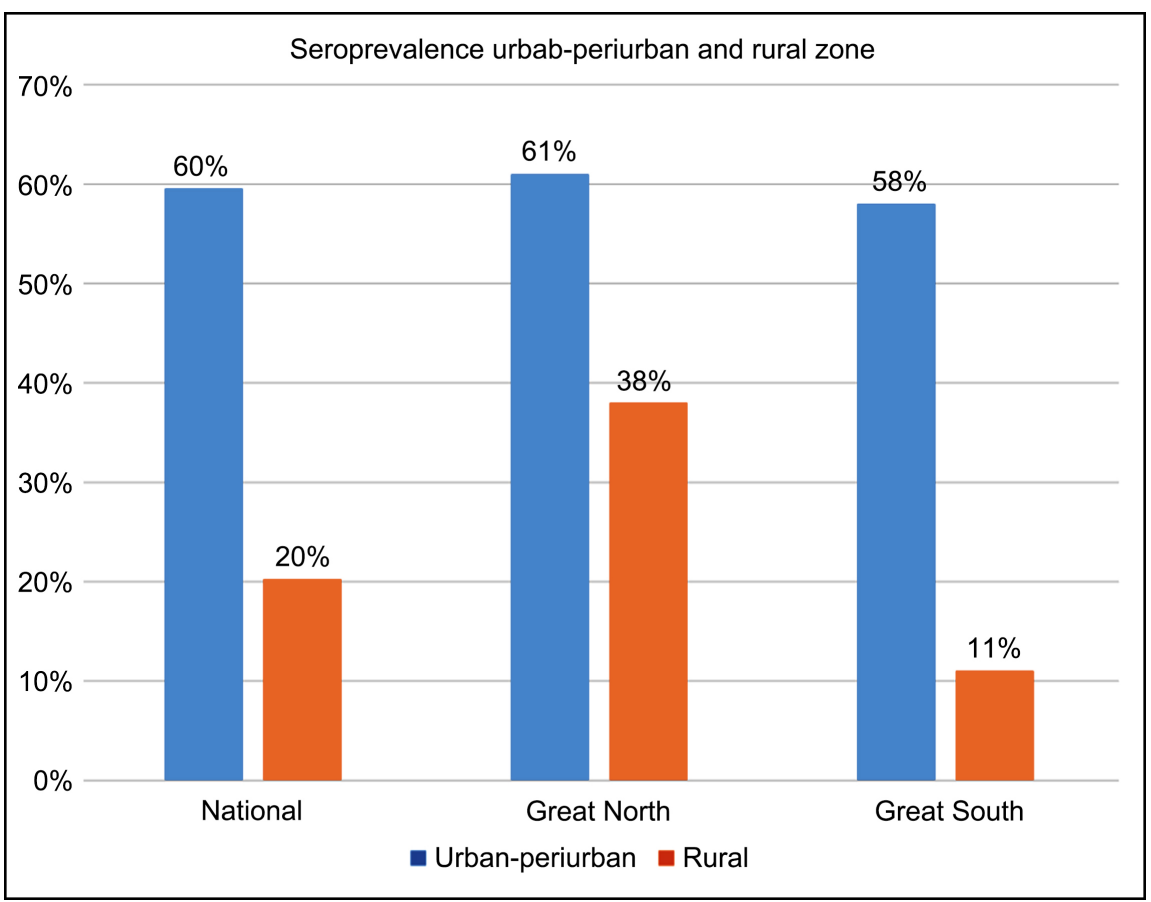

Figure 2. Determination of the level of risk between the urban/peri-urban and the rural areas. 
Table 4. Prevalence ratio (RP) of PPR between urban-peri-urban and rural areas.

\begin{tabular}{ccccccc}
\hline $\begin{array}{c}\text { Livestock } \\
\text { environment }\end{array}$ & $\begin{array}{c}\text { Number } \\
\text { of animals }\end{array}$ & Infected & $\begin{array}{c}\text { Non } \\
\text { infected }\end{array}$ & prevalence & $\begin{array}{c}\text { Prevalence ratio (RP) } \\
\text { (Urban-peri-urban/Rural) }\end{array}$ & CI 95\% \\
\hline Urban & 801 & 477 & 324 & $60 \%$ & & \\
Rural & 821 & 166 & 655 & $20 \%$ & 2.9 & $2.54-3.41$ \\
Total & 1622 & 643 & 979 & $40 \%$ & \\
\hline
\end{tabular}

PPR among small ruminants. These results indicate a probable link between the urban/peri-urban areas where the breeding grounds are implemented and the disease.

\subsection{Period at Risk of PPR Infection Based on Control Data (2005-2010)}

Based on historical data (2005-2010) on PPR syndrome notifications, from the animal disease control network setup in Cameroon in 2004 by the PACE Program (Pan-African Program for the Control of Epizootics), the PPR households had been notified every month throughout the Country with an influx between January and April and a peak was observed in February (Figure 3).

\section{Discussion}

A better knowledge of the epidemiological situation of pests of small ruminants and of the risk factor is very important to adjust the control strategy with a view of eradicating this disease in Cameroon. This study is the first nationally to provide prevalence based on the presence of anti-PPR antibodies in the serum analyzed, PPR is present in all Cameroon regions and the serological prevalence rate was $39.6 \%$ [CI 95\%; 37.6 - 41.6], value appeared rather close to a study carried out in breeding station in the northern zone of the country by Awa et al. Who found a serological prevalence of $29 \%$ in sheep and $44 \%$ in goats [19]. It is also close to studies carried out in other countries. This is the case in Mali where a prevalence of $42.6 \%$ [CI 95\%; 40.9 - 44.3] in small ruminants has been found [10] [20].

The northern zone made up of three regions (Adamawa, North and Far North) shows a high prevalence of 52\% [CI 95\%; 47 - 60] than the southern zone $29 \%$ [CI 95\%; 11 - 57]. This can be justified by the fact that each of these two large areas includes regions which have a fairly similar geographical location and a method of rearing small ruminants. Thus in the northern part of the country, for deficiency reasons in grazing and watering due to a long period of the dry season, the mode of breeding, transhumance and the gathering of animals in the pastures and common watering, remains the most practiced breeding method. On opposition, in the southern zone, a wetter zone characterized by an abundance of pasture, this zone is at less risk despite the rambling which constitutes a risky practice. However, in the southern regions, there is a high prevalence in the 


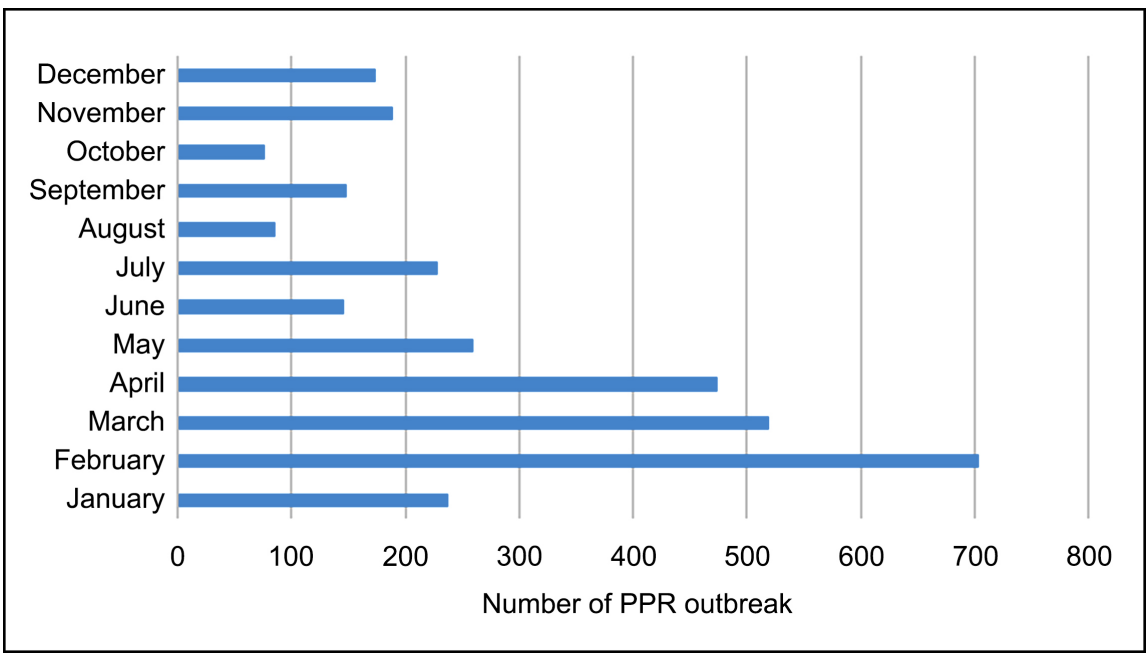

Figure 3. Monthly notification of PPR outbreaks between 2005-2010.

Littoral, South and West regions with 44\%, 54\%, and 70.7\% respectively. These rates can be explained partly by the traffic of small ruminants from the northern part to the southern part, to conquer the markets of large cities (Yaounde, Douala, Bafoussam, ...) and neighboring countries (Gabon, Equatorial Guinea, Nigeria). This argument is consolidated by the results of this study which indicates that the prevalence of animal breeding in the urban/peri-urban area appears in this zone of the country, 5 times more than in the rural areas in comparison to the southern zone where the prevalence between these two areas seems weakly significant with a prevalence report of 1.6 times. The proximity to the market of these cities facilitates the purchase of animals at risk, their introduction into breeding grounds, therefore an increase of this disease in small ruminants found in the urban and peri-urban zones. These results indicate a possible link between these environments where breeding and the disease are implemented [6].

As part of these studies and in order of importance, the five factors of PPR propagation risk are as follows: breeding location, introduction of new animals in the breeding ground, the gathering of animals on pasture or common watering, wandering of animals and transhumance after a poll opinion amongst breeders. The implantation environment appears as one of the most important risk as compared to the other factors. This is explained by the fact that it is an associated factor grouping at least two other factors depending on the zones and breeding methods. The sale of sick animals in livestock market has proven to be a risk factor during the opinion poll, since $68 \%$ of breeders questioned their animals at the livestock market when they notice first mortalities in their breeding environments. Those buying can thus in some cases procure sick animals which enter their breeding environments without respecting quarantine measures. This certifies what Singh et al. noticed; the commerce of small ruminants in markets, where animals from different horizons and sources are put in contact with others hence, favors the transmission of PPRV [12].

By the way, imported animals from the northern zone with an unknown sani- 
tary state and sold in markets then introduced in breeding environments, can develop a sickness in their new environment and transmit to other animals. The gathering of animals during pasture constitute a current practice in the northern regions (Adamawa, north and far north) or in particular towns where one person is in charge of collecting the animals in their various concessions each morning, bringing them to common grazing zones and taking them back in the evening. The transhumance equally constitutes a risk factor because of animals which are brought from neighboring countries (Congo; Gabon; RCA; Equatorial Guinea; Nigeria and Chad) researching pastures.

These two risk factors listed are very important in this zone. Conversely, the wandering of animals is a common risky practice, especially in the southern part of the country and particularly in the rural area. However, this breeding method favors gathering and is a risk factor for the diffusion of the disease. We may expect a high prevalence rate in rural areas, except that in the southern zone, the rural landlocked zones and the limitation see absence of introduction of new animals lowers the exposition to the PPR.

The identification periods at risk of outbreaks from inventories of historic outbreaks from 2005 to 2010 through the epidemiological monitoring system put in place by the PACE in 2004 indicates the occurrence of PPR outbreak in goats and sheep at every moment of the year, but with a high frequency appearance of outbreaks between January and April with its peak in February. This has been noticed in India by Singh et al. who noticed the appearance of outbreaks with a great affluence during the dry and cold seasons (January and February) rather than during the rainy seasons [12] [21]. This could be due to the cold-dry season from December to February associated with the mal nutrition of animals since they are brought from place to place in search for grazing and to be commercialized hence favoring the propagation of the PPR [21] [22]. This was later confirmed by Singh and al who think that the epizootic apparition of PPR is related to the movement of animals and climatic factors which favor the survey and propagation of the virus.

International transhumance, which leads to massive movements of breeders and animals, contributes to the spread of the disease. Indeed, the borders are very porous in the zone which gathers the three Regions of the North (Far-north, North and Adamaoua). There is a large movement of small ruminants which have obtained from the countries of East Africa (Chad, Sudan, Central African Republic), crossing the three Regions to go to the countries of West Africa (Nigeria, Benin). The three Regions are therefore areas of transhumance to foreign herds. This may explain, in part, why the average prevalence rate 52\% [95\% CI; $47-60]$ is higher in this zone which groups together the three Northern Regions compared to the average prevalence rate $29 \%$ [95\% CI; 11 to 57] in zone which groups together the seven Southern Regions [13]

Similary, the movement of these small ruminants in the country constitutes an important propagation factor of the PPR. This is done for commercial reasons 
especially during religious feasts (Tabaski) where, an important number of ruminants are transported to urban centers. Thousands of heads leave the northern zone to the southern zone. Big towns like Yaounde and Douala constitute the essential laying point of these animals. A great number is sent to neighboring countries like Gabon, Equatorial Guinea and Nigeria. Veterinary services lack enough human resources to control this animal circulation within the territory and in frontal zones. When animals are displaced, some infected ones escape from veterinary control and are hence at the origin of local livestock contamination [22]. Moreover, during their displacement from the northern to southern zones, animals can develop a disease then get other animals infected during their transport. This can be one of the reasons of a higher PPR epizootic frequency. Some similar observations have been done throughout the study of the PPR in the tropical humid zone of south Nigeria [23] and in India [12] [24]. Therefore, breeding practices, agro-climatic conditions and geographic locations have an impact on the seasonal distribution of the disease. The movements of animals therefore play an important role in the maintenance and transmission of the PPRV in the nature [23]. Mass vaccination campaigns have to be scheduled taking into account this period.

\section{Conclusion}

This study has permitted us to notice that the PPR is endemic in the whole country and is spread by different breeding modes of different geographic zones, livestock migration, agro-climatic conditions and identified risk factors especially the implantation breeding location in urban/peri-urban areas. The existence of a probable link between the implemented breeding in urban/peri-urban areas and the illness was suspected indicating the interest of purchasing an analytic study for the verification of this probable association.

\section{Acknowledgements}

We would like to thank all the officials of the Ministry of Livestock, Fisheries and the Animal Industries (MINEPIA), the staff of the National Veterinary Laboratory (Garoua and Yaoundé) and the breeders who contributed to accomplishement this study.

Also, thank you to Doctors Gery Wamba (Mfou National Park) and Matchawe Chelea (Institute of Research Medical and Medicinal Plant Study) for their contributions

\section{Conflicts of Interest}

The authors declare no conflicts of interest regarding the publication of this paper.

\section{References}

[1] Gibbs, P.J., Taylor, W.P., Lawman, M.J.P. and Bryant, J. (1979) Classification of Peste des Petits Ruminants Virus as the Fourth Member of the Genus Morbillivirus. 
Intervirology, 11, 268-274. https://doi.org/10.1159/000149044

[2] OIE (2011) Code sanitaire pour les animaux terrestres. http://www.oie.int/fr/normes-internationales/code-terrestre

[3] Sen, A., Saravanan, P., Balamurugan, V. and Rajak, K.K. (2010) Vaccines against Peste des Petits Ruminants Virus. Expert Review of Vaccines, 9, 785-796. https://doi.org/10.1586/erv.10.74

[4] Diallo, A., Taylor, W.P., Lefèvre, P.C., et al. (1989) Attenuation of a Strain of Rinderpest Virus: Potential Homologous Live Vaccine. Revue delevage et de medecine veterinaire des pays tropicaux, 42, 311-319.

[5] Banyard, A.C., Parida, S., Batten, C., Oura, C., Kwiatek, O. and Libeau, G. (2010) Global Distribution of Peste des Petits Ruminants Virus and Prospects for Improved Diagnosis and Control. Journal of General Virology, 91, 2885-2897.

https://doi.org/10.1099/vir.0.025841-0

[6] Tounkara, K. (2018) Epidémiologie d'une maladie transfrontalière des petits ruminants (Pestes des Petits ruminants) à fort impact au Mali. Thèse Pour Obtenir le Grade de Docteur de L'université de Montpellier.

[7] Maganga, G., Verrier, D., Zerbinati, R., Drosten, C., Drexler, J. and Leroy, E. (2013) Molecular Typing of PPRV Strains Detected during an Outbreak in Sheep and Goats in Souther Eastern Gabon in 2011. Virology Journal, 10, Article No. 82.

https://doi.org/10.1186/1743-422X-10-82

[8] Woma, T.Y., Adombi, C.M., Yu, D.A., Qasim, A.M., Sabi, A. and Maurice, N.A. (2016) Co-Circulation of Peste-des-Petits Ruminants Virus Asian Lineage IV with Lineage II in Nigeria. Transboundary and Emerging Diseases, 63, 235-242. https://doi.org/10.1111/tbed.12387

[9] Muniraju, M., Mahapatra, M., Ayelet, G., Babu, A., Olivier, G. and Munir, M. (2010) Emergence of Lineage IV Peste des Petits Ruminants Virus in Ethiopia: Complete Genome Sequence of an Ethiopian Isolate 2010. Transboundary and Emerging Diseases, 63, 435-442. https://doi.org/10.1111/tbed.12287

[10] Karim, A., Bhattacharjee, U., Puro, K., Shakuntala, I., Sanjukta, R. and Das, S. (2016) Detection of Peste des Petits Ruminants Virus and Goatpox Virus from an Outbreak in Goats with High Mortality in Meghalaya State, India. Veterinary World, 9, 1025-1027. https://doi.org/10.14202/vetworld.2016.1025-1027

[11] Shaila, M.S., Shamaki, D., Forsyth, M.A., Diallo, A., Goatley, L. and Kitching, R.P. (1996) Geographic Distribution and Epidemiology of Peste des Petits Ruminants Viruses. Virus Research, 43, 149-153. https://doi.org/10.1016/0168-1702(96)01312-3

[12] Singh, R.K., Balamurugan, V., Bhanuprakash, V., Sen, A., Saravanan, P. and Yadav Pal, M. (2009) Possible Control and Eradication of Peste des Petits Ruminants from India: Technical Aspects. Veterinaria Italiana, 45, 449-462.

[13] MINEPIA (2004) Plan d'urgence contre la peste bovine au Cameroun, dossier du Cameroun à l'OIE pour l'obtention du statut de pays indemne de peste bovine. MINEPIA, Cameroun.

[14] Couacy-Hymann, E., Bodjo, S.C., Danho, T., Koffi Mlibeau, G., et al. (2006) Early Detection of Viral Excretion from Experimentally Infected Goats with Peste-des-Petits Ruminants Virus. Preventive Veterinary Medicine, 78, 85-88. https://doi.org/10.1016/j.prevetmed.2006.09.003

[15] Abegunde, A.A. and Adu, F. (1977) Excretion of the Virus of Peste des Petits Ruminants by Goats. Bulletin of Animal Health and Production in Africa, 25, 307. 
[16] Douffissa, A. (2007) Recueil des textes régissant l'élevage, les pêches et les industries animales au Cameroun.

[17] FAO (2015) Plan strategique de prevention et de lutte contre la peste des petits ruminants (PPR) au cameroun. https://doi.org/10.1007/978-3-662-45165-6_1

[18] Libeau, G., Prehaud, C., Lancelot, R., Colas, F., Guerre, L. and Bishop, D.H.L. (1995) Development of a Competitive ELISA for Detecting Antibodies to the Peste des Petits Ruminants Virus Using a Recombinant Nucleobrotein. Research in Veterinary Science, 58, 50-55. https://doi.org/10.1016/0034-5288(95)90088-8

[19] Awa, D. N., Ngagnou, A., Tefiang, E., Yaya, D. and Njoya, A. (2002) Post Vaccination and Colostral Peste des Petits Ruminants Antibody Dynamics in Research Flocks of Kirdi Goats and Foulbe Sheep of North Cameroon. Preventive Veterinary Medicine, 55, 265-271. https://doi.org/10.1016/S0167-5877(02)00013-2

[20] Kamissoko, B., Sidibé, C.A.K., Niang, M., Samake, K., Traoré, A. and Diakité, A. (2013) Prévalence sérologique de la peste des petits ruminants des ovins et des caprins au Mali. Revue delevage et de medecine veterinaire des pays Tropicaux, 66, 5. https://doi.org/10.19182/remvt.10148

[21] Wosu, L.O. (1994) Current Status of Peste des Petits Ruminants (PPR) Disease in Small Ruminants: A Review Article. Stud Research Veterinary Medicine, 2, 83-90.

[22] Minepia (2010) Rapport Annuel 2010, Projet d'Appui au Développement des Petits Ruminants (PADPR).

[23] Butswat, I., Zahraddeen, D. and Hussaini, A. (2005) Prevalence of Peste des Pestits Ruminant (PPR) and Helminthiasis in Sheep and Goats in Bauchi, Nigeria. Bulletin of Animal Health and Production in Africa, 53, 131-134. https://doi.org/10.4314/bahpa.v53i2.32699

[24] Gardadennec, L. and Lalanne, A. (1942) La peste des petits ruminants.Bulletin des Services de Pélevage et des industries animales de P Afrique occidentale française, $\mathbf{5}$, 16-21. 